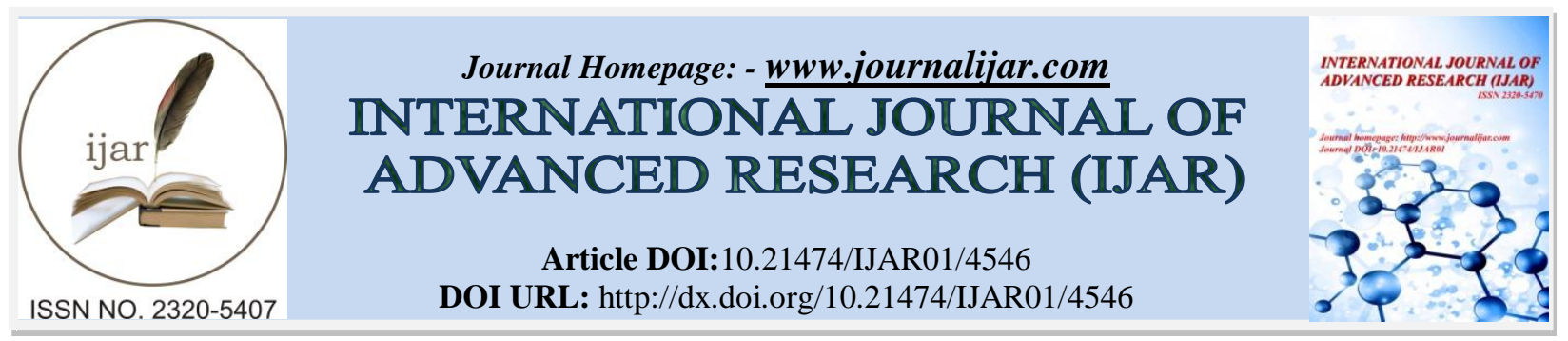

RESEARCH ARTICLE

\title{
BIOCHEMICAL AND MOLECULAR STUDIES ON SUBJECTS WITH SEDENTARY LIFESTYLE AND
} TYPE 2 DIABETES.

\section{*Viji Krishnan", Dinesh Roy $D^{2}$ and Kavya $\mathbf{P}^{2}$.}

1. Department of Biochemistry, Jubilee Mission College and Research Institute, Thrissur - 680005, India.

2. Genetika, Centre for Advanced Genetic Studies, Pettah P O, Thiruvananthapuram - 695024, India.

\section{Manuscript Info}

(.........................

\section{Manuscript History}

Received: 20 April 2017

Final Accepted: 22 May 2017

Published: June 2017

Key words:-

Type 2 diabetes, Sedentary lifestyle, Oxidative stress, Malondialdehyde and

Cytokinesis block micronuclei assay

\section{Abstract}

Type 2 diabetes is most common and comprises of $90 \%$ of people with diabetes around the world. The pathophysiology of type 2 diabetes is complex, but the major risk factors include sedentary lifestyle and behaviors coupled with multifactorial complex interaction between environment and genetic factors. Sedentary lifestyle increases the risk of type 2 diabetes and there is a preponderance evidence for the association of oxidative stress and DNA damage in type 2 diabetes. There is a growing scientific and public interest in connecting oxidative stress with a variety of pathological conditions in type 2 diabetes. The aim of the present study was to verify the level of oxidative stress that may be attributed to type 2 diabetes by Malondialdehyde (MDA) and to determine the resulting DNA damage by cytokinesis block micronuclei assay. An attempt is also being made to correlate the risk factor with type 2 diabetes. Various demographic, lifestyle, clinical and biochemical characteristics of the study subjects with type 2 diabetes was analyzed. The study was performed in 68 study subjects and 32 healthy control subjects. These study subjects were observed with raised level of MDA and increased frequency of micronuclei. This study indicates that there is a significant correlation with risk factors and mean CBMN frequency in type 2 diabetic patients.

Copy Right, IJAR, 2017,. All rights reserved.

\section{Introduction:-}

Type 2 diabetes (T2DM) is typically a chronic disease associated with a ten-year-shorter life expectancy (Imperatore et al., 2012). It is two to four times the risk of cardiovascular disease, including ischemic heart disease and stroke (Pan et al., 2015). Sedentary lifestyle is an important risk factor for type 2 diabetes. Sedentary behaviors such as prolonged screen time, sitting time, driving and reading time among others are behaviors strongly associated with increased eating and weight gain which favor diabetes mellitus (Brannon and Feist, 2007).

Globally, T2DM has become one of the most important chronic public health problems (International Diabetes Federation, 2003). T2DM, which is a condition characterized by both insulin resistance (poor tissue insulin sensitivity) and impaired insulin secretion from the pancreatic $\beta$-cells (Petrie, 2011). T2DM is a complex heterogeneous group of metabolic condition characterized by elevated levels of serum glucose. $\beta$-cell dysfunction

\section{Corresponding Author:-Viji Krishnan}


includes abnormalities in pulsatility and in kinetics of insulin secretion, quantitative and qualitative abnormalities of insulin, $\beta$-cell loss and its progression (Roglic, 2000).

A number of lifestyle factors are known to be important to the development of T2DM. These are physical inactivity, sedentary lifestyle, cigarette smoking and generous consumption of alcohol (Hu, 2011). The word "Sedentary" is coined from the Latin word "Sedere" which means "to sit" hence sedentary behavior is a term used to characterize those behaviors that are associated with low energy expenditure. This includes prolonged sitting at work, home, business centers, long screen time, car driving and leisure time. A person who lives a sedentary lifestyle may be known as a "Couch Potato" (Owen, 2010). Sedentary lifestyle as distinct class of behaviors is characterized by little or no physical movement and low energy expenditure less than 1.5 Metabolic Equivalent Task (METs). MET is used to assess the energy expenditure during activities (Achalu, 2008). Other risk factors such as those with a family history of diabetes have three times greater chance to get T2DM compared to those without it. Many factors like obesity, diet and stress which are considered more important risk factors (Acemoglu et al., 2001).

In diabetes, oxidative stress is caused by both an increased formation of plasma free radicals and a reduction in antioxidant defenses. Hyperinsulinemia and hyperglycemia may enhance the production of free radicals and induce oxidative stress that may also contribute to increased risk for coronary artery disease in diabetes (Ceriello, 2006). The link between oxidative stress and the development and progression of type 2 diabetes mellitus and its complications is still not fully understood. It can be assessed by measurement of reaction products of oxidative damage, like lipid peroxidation, DNA oxidation and protein oxidation (Halliwell, 1997). Diabetics may have a defective antioxidant status as a result of either increased use or reduced intake of antioxidant to fight the excessive free radical production that is associated with diabetes mellitus (Ahmad et al., 2003).

The sequelae of type 2 diabetes mellitus (hyperglycaemia and hyperlipidaemia) may not only cause elevated peroxidation, but pre-existing high rates of lipid peroxidation may predispose to and accelerate the development of diabetes especially upon exposure to a pro-oxidant challenge (Laight et al., 2000). Such elevated rates may reflect poor antioxidant intake (Salonen et al., 1995; Ford, 2001), but may also involve inherited differences in rates of peroxidation and metabolism of lipid peroxides (Halliwell, 2000). MDA is a marker used to detect oxidative stress. MDA is an organic compound derived from the lipid per-oxidation of poly unsaturated fatty acid. It is a mutagenic bi product.

DNA damage may be associated with type 2 diabetes mellitus and its complications mainly through oxidative stress. The elevated ROS in diabetes can cause strand breaks in DNA and base modifications including oxidation of guanine residues to 8-hydroxy 20-deoxy-guanosine, an oxidized nucleoside of DNA, which is the most frequently detected and studied DNA lesion (Dandona et al., 1996). DNA damage and oxidative stress have also been implicated in diverse disease such as brain injury, pulmonary diseases, and other chronic inflammation related disorders. It is well known that free radicals can cause oxidative stress which leads to protein, lipid, and DNA modifications that cause cellular dysfunction and this could have teratogenic or carcinogenic consequences (Yfjord and Bodvarsdottir, 2005). No previous studies were conducted to evaluate oxidative stress and DNA damage among subjects associated with type 2 diabetes and sedentary lifestyle. Hence the present study was undertaken to aware people about oxidative stress and DNA damage among subjects with type 2 diabetes and sedentary lifestyle.

\section{Material and Methods:-}

Sixty eight study subjects with a clinical diagnosis of type 2 diabetes were referred from various clinics of Kerala to Genetika, Centre for Advanced Genetic studies, Trivandrum. Thirty two healthy subjects without any chronic illness were also selected as control for this study. Detailed demographic, lifestyle, clinical and biochemical characteristics of the subjects were recorded using proforma.

Seven $\mathrm{ml}$ of blood sample was collected by venipuncture. Two $\mathrm{ml}$ of blood was transferred into sodium heparinized vacuutainers for quantifying the extent of somatic DNA damages by Cytokinesis-Block Micronuclei (CBMN) assay. The remaining five $\mathrm{ml}$ of blood was transferred into a plain tube. Blood was allowed to clot, serum separated immediately. Blood sugar and lipid profile were estimated using semi-automated clinical chemistry analyzer. The level of the serum lipid peroxide marker, MDA was determined using thiobarbituric acid as main reagent and measuring these values on photoelectric colorimeter at $540 \mathrm{~nm}$. 
Two ml blood was added to a culture tube containing $10 \mathrm{~mL}$ RPMI 1640 medium supplemented with 100units/mL penicillin, $100 \mu \mathrm{g} / \mathrm{mL}$ streptomycin, $15 \%$ fetal bovine serum and $10 \mu \mathrm{g} / \mathrm{mL}$ phytohaemagglutinin. Cytochalasin B was added to the cultures at a final concentration of $4.5 \mu \mathrm{g} / \mathrm{mL}$ (Sigma) after $44^{\text {th }}$ hours of initiation of cells with phytohaemagglutinin. Cells were harvested after $72^{\text {th }} \mathrm{hr}$ incubation, and they were treated with a hypotonic $\mathrm{KCl}$ solution $(0.075 \mathrm{M} \mathrm{KCl})$ for $1 \mathrm{~min}$ and fixed in fresh fixative solution (methanol: acetic acid, 3:1). The cells were dropped onto slides and the slides were air dried and stained with 10\% Giemsa. Micronucleated cells were analyzed under light microscopy at 100X magnification. The number of micronuclei is not less than 1000 binucleated cells were scored and the distribution of micronuclei among binucleated cells was recorded.

\section{Observations and Results:-}

The present study consists of 68 study subjects and 32 control subjects. Study subjects were in the age range of 23 to 59 years with mean age of 34.74 years and control subjects with age range of 30 to 40 years with mean age of 35.04 years. Subjects in this study group with type 2 diabetes and having a sedentary lifestyle. Majority of the subjects were male.

Table 1:- Distribution of mean CBMN frequency and mean MDA value according to study and sontrol subjects

\begin{tabular}{|c|c|c|c|}
\hline Subjects & Number & Mean CBMN frequency & Mean MDA value \\
\hline Study subjects & 68 & 12.83 & 2.24 \\
\hline Control subjects & 32 & 9.54 & 1.19 \\
\hline
\end{tabular}

The distribution of mean CBMN frequency of study subjects was 12.83 and control subjects was 9.54. The mean MDA value of the study subjects was 2.24 and control subjects was 1.19. The mean CBMN frequency and mean MDA value of the study subjects was greater than the control subjects.

Table 2:- Distribution of mean CBMN frequency and mean MDA value according to demographic characteristics

\begin{tabular}{|l|l|l|r|r|}
\hline Variables & Category & Number (Percentage) & Mean CBMN frequency & Mean MDA value \\
\hline \multirow{5}{*}{ Age (Years) } & $<35$ & $41(60.29 \%)$ & 12.67 & 2.15 \\
\cline { 2 - 5 } & 35 to 50 & $17(25 \%)$ & 13.03 & 2.26 \\
\cline { 2 - 5 } & $>50$ & $10(14.70 \%)$ & 13.14 & 2.34 \\
\hline \multirow{3}{*}{ Sex } & Male & $54(79.49 \%)$ & 12.87 & 2.25 \\
\cline { 2 - 5 } & Female & $14(20.58 \%)$ & 12.82 & 2.24 \\
\hline \multirow{3}{*}{ Weight $(\mathrm{cm})$} & $150-168$ & $39(57.35 \%)$ & 12.92 & 2.27 \\
\cline { 2 - 5 } & $169-186$ & $29(42.64 \%)$ & 12.85 & 2.24 \\
\cline { 2 - 5 } & $40-65$ & $19(27.94 \%)$ & 12.79 & 1.75 \\
\cline { 2 - 5 } & $66-90$ & $40(58.82 \%)$ & 12.85 & 2.27 \\
\cline { 2 - 5 } & $91-125$ & $9(13.23 \%)$ & 12.95 & 2.32 \\
\hline \multirow{3}{*}{ BMI $\left(\mathrm{kg} / \mathrm{m}^{2}\right)$} & $<25$ & $19(27.94 \%)$ & 12.73 & 2.12 \\
& $25-29$ & $32(47.05 \%)$ & 12.80 & 2.26 \\
\cline { 2 - 5 } & $\geq 30$ & $17(25 \%)$ & 13.06 & 2.28 \\
\hline
\end{tabular}

The subjects were grouped based on their demographic characteristics such as age, sex, height, weight and BMI (Table 1). Among the 68 study subjects, age of the subjects were grouped into $<35,35$ to 50 and $>50$ years. Majority of the subjects were belonged to age between $<35$ years $(n=41)$. Highest mean CBMN frequency (13.14) and mean MDA value (2.34) were shown by subjects with age $>50$ years. Majority of the subjects were male and they had highest micronuclei frequency and MDA value. Weight and BMI of the subjects were showing those who are overweight or obese such subjects having increased risk with increased micronuclei frequency. Subjects with BMI $>30 \mathrm{~kg} / \mathrm{m}^{2}$ were showed highest mean CBMN frequency of 13.06 .

Table 3:- Distribution of mean CBMN frequency and Mean MDA value according to clinical characteristics.

\begin{tabular}{|c|c|c|c|c|}
\hline Variables & Category & Number (Percentage) & Mean CBMN frequency & Mean MDA value \\
\hline \multirow{2}{*}{ H/o Hypertension } & Yes & $58(85.29 \%)$ & 13.16 & 2.51 \\
\cline { 2 - 5 } & No & $10(14.70 \%)$ & 12.80 & 2.29 \\
\hline \multirow{2}{*}{ H/o Dyslipidemia } & Yes & $19(27.94 \%)$ & 12.87 & 2.53 \\
\cline { 2 - 5 } & No & $49(72.05 \%)$ & 12.66 & 2.17 \\
\hline
\end{tabular}


According to clinical characteristics of subjects, majority of the subjects with H/o hypertension ( $\mathrm{n}=58$ ) and they have highest mean CBMN frequency (13.16) and MDA value (2.51). Subjects having H/o dyslipidemia showed highest mean CBMN frequency (12.87) and MDA value (2.53).

Table 4:- Distribution of mean CBMN frequency and mean MDA value according to lifestyle characteristics

\begin{tabular}{|l|l|l|r|r|}
\hline Variables & Category & $\begin{array}{l}\text { Number } \\
\text { (Percentage) }\end{array}$ & $\begin{array}{l}\text { Mean CBMN } \\
\text { frequency }\end{array}$ & $\begin{array}{l}\text { Mean MDA } \\
\text { value }\end{array}$ \\
\hline \multirow{2}{*}{ Habit of smoking } & Yes & $22(32.35 \%)$ & 12.94 & 2.58 \\
\cline { 2 - 5 } & No & $46(67.64 \%)$ & 12.79 & 2.23 \\
\hline \multirow{3}{*}{ Habit of drinking } & Yes & $32(47.05 \%)$ & 12.97 & 2.25 \\
\cline { 2 - 5 } & No & $36(52.94 \%)$ & 12.64 & 2.24 \\
\hline \multirow{3}{*}{ Type of diet } & Vegetarian & $8(11.76 \%)$ & 12.82 & 2.27 \\
\cline { 2 - 5 } & $\begin{array}{l}\text { Non } \\
\text { vegetarian }\end{array}$ & $60(88.23 \%)$ & 13.15 & 2.50 \\
\hline \multirow{2}{*}{$\begin{array}{l}\text { Frequency of fruit consumption in } \\
\text { week }\end{array}$} & Good & $15(22.05 \%)$ & 12.69 & 2.13 \\
\cline { 2 - 6 } & Average & $40(58.82 \%)$ & 12.78 & 2.22 \\
\cline { 2 - 5 } & Low & $13(19.11 \%)$ & 13.15 & 2.28 \\
\hline \multirow{2}{*}{ Consumption of junk food } & Yes & $56(82.35 \%)$ & 12.90 & 2.41 \\
\cline { 2 - 5 } & No & $12(17.64 \%)$ & 12.81 & 2.21 \\
\hline \multirow{2}{*}{ Exercise } & Yes & $25(36.76 \%)$ & 12.86 & 2.24 \\
\cline { 2 - 5 } & No & $43(63.26 \%)$ & 12.80 & 2.25 \\
\hline \multirow{2}{*}{ Working hours } & $<8$ hours & $8(11.76 \%)$ & 13.7 & 2.23 \\
\cline { 2 - 5 } & $\geq 8$ hours & $60(88.23 \%)$ & & 2.61 \\
\hline
\end{tabular}

Lifestyle characteristics of study subject were observed in table 4. Subjects having the habit of smoking and drinking showed highest MDA value and mean CBMN frequency. Majority of the subjects were non vegetarians $(n=60)$ having highest micronuclei frequency (13.15). Subjects who consume junk food showed highest mean CBMN frequency (12.90). Highest mean CBMN frequency was showed by subjects without doing exercise (12.86). Subjects, who work > 8 hours a day showed highest mean CBMN frequency (13.7) and MDA value (2.61).

Table 5:- Distribution of mean CBMN frequency and mean MDA value according to biochemical characteristics

\begin{tabular}{|l|l|l|r|r|}
\hline Variables & Category & Number (Percentage) & Mean CBMN frequency & Mean MDA value \\
\hline Fasting blood sugar (mg/dl) & $110-125$ & $29(42.64 \%)$ & 12.28 & 2.18 \\
\cline { 2 - 5 } & $>125$ & $39(57.35 \%)$ & 12.89 & 2.25 \\
\hline \multirow{2}{*}{ Total cholesterol (mg/dl) } & $\leq 200$ & $22(32.35 \%)$ & 12.70 & 2.05 \\
\cline { 2 - 5 } & $>200$ & $46(67.64 \%)$ & 12.88 & 2.33 \\
\hline \multirow{2}{*}{ High density lipoprotein $(\mathrm{mg} / \mathrm{dl})$} & $\leq 40$ & $41(60.29 \%)$ & 12.83 & 2.26 \\
\cline { 2 - 5 } & $>40$ & $27(39.70 \%)$ & 12.80 & 2.24 \\
\hline Low density lipoprotein $(\mathrm{mg} / \mathrm{dl})$ & $<130$ & $16(23.52 \%)$ & 12.77 & 2.07 \\
\cline { 2 - 5 } & $\geq 130$ & $52(76.47 \%)$ & 13.12 & 2.28 \\
\hline Triglycerides (mg/dl) & $\leq 150$ & $28(41.17 \%)$ & 12.73 & 2.20 \\
\cline { 2 - 5 } & $>150$ & $40(58.82 \%)$ & 12.89 & 2.24 \\
\hline
\end{tabular}

Biochemical characteristics of study subjects such as fasting blood sugar, total cholesterol, high density lipoprotein, low density lipoprotein and triglycerides were observed. From the table, diabetic subjects (FBS $>125 \mathrm{mg} / \mathrm{dl}$ ) showed highest mean CBMN frequency (12.89) than prediabetic subjects. Highest mean CBMN frequency were showed by subjects with hypercholesterolemia (TC $>200 \mathrm{mg} / \mathrm{dl}$ ). Subjects with lowest level of HDL cholesterol ( $\leq 40 \mathrm{mg} / \mathrm{dl}$ ) were showed highest mean CBMN frequency (12.83) and MDA value (2.26). Subjects having high values of LDL cholesterol $(\geq 130 \mathrm{mg} / \mathrm{dl})$ and triglyceride $(>150 \mathrm{mg} / \mathrm{dl})$ were showed highest mean CBMN frequency and MDA value.

\section{Discussion:-}

Baan et al., (1999) attributed increasing prevalence of type 2 diabetes risks with advancing age. In the present study, subjects in the age group of $>50$ years observed increase in mean CBMN frequency (13.14) with progression of age. 
Dyslipidemia has been reported as a risk factor for type 2 diabetes by several prospective studies High plasma triglycerides and low plasma HDL cholesterol levels are both seen in the insulin resistance syndrome, which is a prediabetic state suggesting that nonfasting triglycerides and HDL cholesterol levels reflect the degree of insulin resistance (Pont et al., 2002). Similarly the present study found that increased mean CBMN frequency (12.87) in subjects with H/o dyslipidemia.

A study conducted in Ahmad et al., (2003) showed that 21\% patients with type-2 diabetes had raised serum cholesterol $(>200 \mathrm{mg} / \mathrm{dl})$ and $34.2 \%$ patients have raised triglycerides in serum $(>150 \mathrm{mg} / \mathrm{dl})$. The present study shows increased mean CBMN frequency in subjects with increased level of total cholesterol $(>200 \mathrm{mg} / \mathrm{dl})$ and triglycerides (>150 mg/dl).

Several prospective studies reported that current smoking is a risk factor for developing type 2 diabetes (Hu et al., 2011; Hur et al., 2007 and Sairenchi et al., 2004). Similarly the present study found that increase in mean CBMN frequency (12.94) is found in patients with habit of cigarette smoking. The findings from the Health Study in NordTrondelag (HUNT) study, although based on few patients, suggested that moderate intake of alcohol is associated with a reduced risk of Latent autoimmune diabetes of adults (LADA) (Baliunas et al., 2009). But in the present study found that increase in mean CBMN frequency (12.97) in patients with habit of drinking.

Regarding physical activity, Devlin et al., (1992) found that among patients with type 2 diabetes, short period of exercise can lower plasma glucose level by enhancing the effect of insulin and more extended exercise training may improve the action of insulin and glucose tolerance. Present study showed that increase in mean CBMN frequency (12.86) is found in patients without exercise.

Few studies, however, have examined the association between sedentary behaviors (prolonged television watching and obesity) and diabetes. Using data from a large prospective cohort study, that increasing TV watching is strongly associated with increased risk of type 2 diabetes, obesity and weight gain (Rocchini, 2002). In the present study shows that sedentary lifestyle increases the risk of developing type 2 diabetes.

According to Mandal et al., (2010) increased levels of serum MDA in cases of type 2 diabetes with complications in comparison to cases of diabetes mellitus without complications indicate more association of oxidative stress with diabetic complications. This association can also be explained in relation with the present study. In the present study shows that the MDA value was higher for study subjects (2.24) than for control subjects (1.19).

\section{Summary and Conclusion:-}

In short, the present study involves evidences of increased oxidative stress and DNA damage among subjects with type 2 diabetes and sedentary lifestyle. The present study suggests that the sedentary lifestyle increase all causes of mortality and its consequences are extremely serious. Diabetes has a great influence on sedentary lifestyle and physical inactivity. The demographic, lifestyle, clinical and biochemical characteristics of the study subjects correlate with higher level of mean CBMN frequency and MDA value. The present findings imply sedentary lifestyle is associated with oxidative stress, which, in turn, propagates type 2 diabetes and other related complications. Therapies, consumable or behavior having capacity to reduce the impact of oxidative stress, may be beneficial to deplete type 2 diabetic associated interventions; thus increase antioxidant defenses could be useful to prevent and treatment for diabetics. Individuals with an absolute deficiency of insulin require insulin replacement therapy, which is given through injections. Insulin resistance can be corrected by dietary modifications and exercise. Other goals of type 2 diabetes management are to prevent or treat the many complications that can result from the disease itself. Furthermore it appears that the sedentary lifestyle is one of the major factors contributing to type 2 diabetic; thus suggest reducing prolonged sitting with regular exercise and weight management.

\section{Reference:-}

1. Acemoglu, H., Ceylan, A., Saka, G., Plalanci, Y., Erten, M. and Turgut, S. et al. (2001). Risk factors for diabetes in South Eastern Anatolia of Turkey, Int J Epidemiol;3(1):.1540-2614.

2. Achalu, (2008). Health Services and Health Care Delivery Systems. Port-Harcourt, Pam UniquePublishing Co.Ltd.

3. Ahmad, M., Ahmad, K.M., Khan A.S. (2003). Naturally occurring antioxidant vitamin levels in patients with type 2 diabetes. JAyub med Coll Abbotabad; 15(1). 
4. Baan, C.A., Nusselder, W.J., Barendregt, J.J., Ruwaard, D., Bonneux, L., et al. (1999). The burden of mortality of diabetes mellitus in the Netherlands. Epidemiology, 10: 184-187.

5. Baliunas, D.O., Taylor, B.J., Irving, H., Roerecke, M., Patra, J., Mohapatra, S., Rehm, J. (2009). Alcohol as a risk factor for type 2 diabetes: A systematic review and meta-analysis. Diabetes Care;32: 2123 -2132.

6. Brannon and Feist. (2007). Health Psychology An Introduction to Behaviour and Health 6th Edition, United State of America, Thomspon Wadsworth Publisher.

7. Ceriello, A. (2006). Oxidative stress and diabetes-associated complications. Endocr. Pract. 12 (1).60-62.

8. Dandona, P., Thusu, K., Cook, S., et al. (1996). Oxidative damage to DNA in diabetes mellitus. Lancet;347: 444-445.

9. Devlin, J.T. (1992). Effect of exercise on insulin sensitivity in humans. Diabetes care 1992.15. 1701.

10. Ford, E., S. (2001). Vitamin supplement use and diabetes mellitus incidence among adults in the United States. Am J Epidemiol; 153:892-7.

11. Halliwell, B. (2000). Lipid peroxidation, antioxidants and cardiovascular disease: how should we move forward? Cardiovasc Res; 47:410-8.

12. Halliwell, B. (1997). Antioxidants and human disease: a general introduction, Nutr Rev; 55:1997. $44-49$.

13. Hu, F. B., Manson, J. E., Stampfer, M. J. (2011). Diet, lifestyle and risk of type 2 diabetes mellitus in women. N Engl J Med; 161:1581-1586.

14. Hur, N.W., Kim, H. C., Nam, C. M., Jee SH, Lee HC, Suh I. (2007). Smoking cessation and risk of type 2 diabetes mellitus: Korea medical insurance corporation study. Eur J Cardiovasc Prev Rehabil.14(2):244-9.

15. Imperatore, G., Boyle, J. P., Thompson, T.J., Case, D., Dabelea, D., et al. (2012). Projections of type 1 and type 2 diabetes burden in the USA population. ITHS; 35: 2515-2520.

16. International Diabetes Federation, (2003). Diabetes Atlas. 2nd edition. Brussels: Gan D, Ed. Belgium.

17. Laight, D.W., Carrier, M. J. and Anggard, E. E. (2000). Antioxidants, diabetes and endothelial dysfunction. Cardiovasc Res.47:457-64.

18. Mandal, B., Bandyopadhyay R., Chakrabarti S., Bandyopadhyay T.K. (2010). Assessment of oxidative stress in patients of diabetes mellitus with and without complications. JIACM.11:20-25.

19. Pan, A., Wang, Y., Talaei, M., Hu, F. B., Wu, T. (2015). Relation of active, passive, and quitting smoking with incident type 2 diabetes: a systematic review and metaanalysis. The lancet Diabetes \& Endocrin. 3: 958967

20. Petrie, J. R., Person, E. R. and Sutherland C. (2011). Implications of genome wide association studies for the understanding of type 2 diabetes pathophysiology. Biochemical Pharmacology: 2011. 81: 471-477.

21. Pont, F., Duvillard, L., Florentin, E., Gambert, P., Verge`s, B. (2002). High-density lipoprotein apolipoprotein A-I kinetics in obese insulin resistant patients. An in vivo stable isotope study. Int. J. Obes. Relat. Metab. Disord. Rocchini, A., P. (2002). Childhood obesity and diabetes epidemic. New Engl J Med. 346:854-855.

22. Roglic, G., Unwin, N., Bennett, P. H., Mathers, C., Tuomilehto, J., Nag, S., Connolly, V., King, H. (2005). The burden of mortality attributable to diabetes: realistic estimates for the year 2000. Diabetes Care; 28:21305.

23. Sairenchi, T., Iso, H., Nishimura, A., Hosoda, T., Irie, F., Saito, Y., et al. (2004). Cigarette smoking and risk of type 2 diabetes mellitus among middle-aged and elderly Japanese men and women. Am J Epidemiol; 160(2):158-62.

24. Salonen, J. T., Nyyssonen, K., Tuomainen, T. P., Maenpaa, P. H., Korpela, H. et al. (1995). Increased risk of non-insulin dependent diabetes at low plasma vitamin E concentrations: a four year follows up study in men. BMJ; 1995. 311: 1124-7.

25. Yfjord, J., Bodvarsdottir, S. (2005). Genomic instability and cancer: networks involved in response to DNA damage. 2005. Mutat Res;592:18-28. 5. 